Terr. Atmos. Ocean. Sci., Vol. 18, No. 5, 879-900, December 2007

\title{
Analysis of Standing Waves on GPR Hyperbolic Travel-Time Responses - Case Studies in a Fractured Granitic Rock and a Deteriorating Coastal Structure
}

\author{
Yun-Li Chen ${ }^{1}$, Joseph Jinder Chow ${ }^{1,}{ }^{*}$, and How-Wei Chen ${ }^{2}$
}

(Manuscript received 27 October 2006, in final form 26 April 2007)

\begin{abstract}
Utilizing Ground Penetrating Radar (GPR), emitted electromagnetic (EM) standing waves can be generated in underground voids. This phenomenon can be employed for the detection of subterranean voids and fractures when one has a proper understanding of relation between the widest inner length in an underground vacant space and half an EM wavelength. In this study, indoor and outdoor small-scale experiments verified the generation of EM standing waves. These responses were then applied in an arched-top cave covered by a single layer of backfill at Gongzihliao, Taiwan. Further studies were carried out at two other sites, including a fracture located in a granite mountain without regolith on the surface at Kinmen, and a deteriorating fishing port in Nanfangao, northeast Taiwan. Applying a band-pass filter with bandwidth narrower than a typical two-octave bandwidth produced the required standing waves with recognizable positions of minimum amplitude. A hyperbolic travel-time (HTT) curve revealing the minimum amplitude, known as standing-wave nodes, indicates the presence of an underground hollow diffractor with the widest inner length in the vacant space being larger than half an EM wavelength. However, a HTT curve without nodal points signifies a hollow object with the widest inner length smaller than half an EM wavelength or an underground solid diffractor. An underground arched-top cave was detected by nodal points in the arc-like curves. When emitting the radar waves toward a wall, the
\end{abstract}

\footnotetext{
${ }^{1}$ Institute of Applied Geoscience, National Taiwan Ocean University, Keelung, Taiwan, ROC

2 Institute of Geophysics, National Central University, Chung-Li, Taiwan, ROC

* Corresponding author address: Prof. Joseph Jinder Chow, Institute of Applied Geoscience, National Taiwan Ocean University, Keelung, Taiwan, ROC; E-mail: jdchow@mail.ntou.edu.tw doi: 10.3319/TAO.2007.18.5.879(T)
} 


\begin{abstract}
interval of the nodes was used for estimating the wavelength of receiving GPR signals. Identifying the occurrence of nodal points in HTT or HTTlike curves in radargrams may assist the GPR interpreting work for underground tunnels, drainages, cavities, fractures, or solid objects.
\end{abstract}

\title{
(Key words: Standing wave, Hyperbola, Cave, Ground penetrating radar)
}

\section{INTRODUCTION}

Ground penetrating radar (GPR) can be used to explore near-surface strata using the electromagnetic (EM) waves within a frequency ranging from $\mathrm{MHz}$ to $\mathrm{GHz}$. Its applications include the mapping of fractures (Grandjean and Gourry 1996; Grasmueck 1996; Du 2000), caves in subsurface karstic features and limestone (Chamberlain 2000; Beres et al. 2001) and many environmental and engineering problems (Meier et al. 1997).

When detecting voids, reverberative radar signals could occur due to the EM waves being multi-reflected from the top and bottom boundaries of voids (Malagodi et al. 1996; Chamberlain 2000; Lin 2000). The groundwater table, horizontal or inclined joints and other subsurface discontinuities could also create these reflections (Nakashima et al. 2001; Porsani et al. 2006). In addition, hyperbolic diffraction patterns will be generated as radar waves are scattered by deep caves or underground solid diffractors (Bruschini et al. 1998; Beres et al. 2001). Thus, diffraction and resonance encoded in a GPR profile could be an effective means of identifying caves, solid objects, or underground discontinuities. Radar standing waves can be generated from an EM-wave source (Jackson 1998). EM standing waves may also occur when using GPR to detect caves (Somer et al. 2005). Migration is often used to move dipping reflectors to their true subsurface and collapse the hyperbola in GPR data processing (Daniels 2004). The arc-like curve in a radargram generated from an arc-like boundary may be removed or destroyed. The possibility exists that we may be able to recognize EM standing-wave nodes occurring in the hyperbolic travel-time (HTT) curve to detect the underground voids, drainages, or tunnels.

EM standing waves can be generated when the length between two boundaries satisfies the integral condition of half an EM wavelength (Cheng 1989). Standing waves generated by sound have been used in the acoustic absorption coefficient of materials (Peng and Ling 2005), by water waves to induce pressure on walls (Prabhakar and Sundar 2001). A pure radar standing wave, peaks or nulls being at the same points, occurs between the boundaries of perfect conductors during the emission of EM waves (Inan and Inan 1999). However, the media between two reflecting boundaries in general are not perfect conductors and may be sometimes filled with air. Thus the total electric field $E(z)$ inside the boundaries is the superposition of incident and reflected waves (Cheng 1989):

$$
E(z)=E_{i}(z)+E_{r}(z)=a_{x} E_{i 0}\left(e^{-i \beta z}+\Gamma e^{+i \beta z}\right)=a_{x} E_{i 0}\left[\tau e^{-i \beta z}+\Gamma(2 i \sin \beta z)\right],
$$

where $\Gamma=\frac{E_{r 0}}{E_{i 0}}=\frac{\eta_{2}-\eta_{1}}{\eta_{2}+\eta_{1}}$ (reflected coefficient), $\tau=\frac{E_{t 0}}{E_{i 0}}=\frac{2 \eta_{2}}{\eta_{2}+\eta_{1}}$ (transmitted coefficient), 
$\eta_{1}$ is the intrinsic impedance of medium $1, \eta_{2}$ is the intrinsic impedance of medium 2, $E_{i 0}$ is the incident electric field at the boundary, $E_{r 0}$ is the reflected electric field at the boundary, $a_{x}$ is the unit vector in $\mathrm{x}$ direction, $\beta$ is the wave number $\left(\frac{2 \pi}{\lambda}, \lambda\right.$ is the wavelength of EM wave) and $\mathrm{z}$ is the propagating direction. Because the transmitted waves, $E_{t 0}$, propagate into the boundary and do not contribute to the reflected field for generating standing waves inside the boundaries, they are not included in the term of $E(z)$. $E(z)$ is mainly composed of two parts: a traveling wave with an amplitude $\tau E_{i 0}$ and a standing wave with an amplitude $2 \Gamma E_{i 0}$. Because of the existence of a traveling wave, $E(z)$ will not become zero at a fixed distance between two boundaries. The pure non-zero term of a traveling wave is revealed at locations of relative minimum amplitude, known as standing-wave nodes.

We assume that the boundaries are planar and perpendicular to the propagating direction of EM waves (Jackson 1998) and electrical properties are constant within the same layer (Cai and McMechan 1999). The total electric field $E(z)$ inside the resonant cavity can be rewritten as:

$$
E(z)=a_{x} E_{i 0} e^{-i \beta z}\left(1+\Gamma e^{+i 2 \beta z}\right)
$$

The minimum value of $E(z)$ is $E_{i 0}(1-\Gamma)$, which occurs at $z=\frac{(2 n+1) \lambda}{4}(n=0,1,2, \ldots)$. The $z(s)$ are the positions of standing-wave nodes. The distance between adjacent nodes is the half wavelength of EM waves (Fig. 1).

From the occurrence of the nodes, the wavelength of reflected EM waves emitted by GPR can be acquired. A HTT curve can be traced from a near-offset GPR profile when EM waves are scattered from an underground object. The objective of this study is to use EM standing waves to determine the nodal points in arc-like and HTT curves by emitting radar waves on an underground vacant space with the widest inner length larger or smaller than the half EM wavelength. Appropriately interpreting this work could assist in the use GPR in the estimation of void volume.

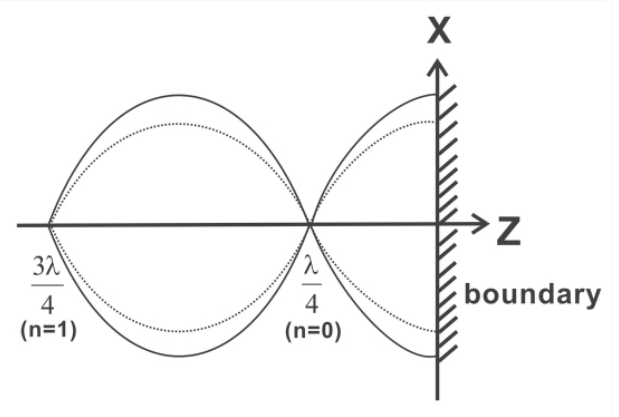

Fig. 1. Schematic generation of EM standing waves. 


\section{EXPERIMENT, DATA PROCESSING, AND RESULTS}

The experiments were done using a GSSI (Geophysical Survey System Inc.) Sir-20 GPR system. A portable laptop computer with the appropriate software (GSSI 2003) was used to control the $1.5-\mathrm{GHz}$ and $500-\mathrm{MHz}$ antennae for field studies. The experiments included the following parts: (1) small-scale controlled experimental tests; (2) applying the model of part I in a size-measured arched top cave and (3) field application by detecting a fracture in a granitic rock and a void in a deteriorating coastal structure.

The frequency spectrum of a GPR system typically has a two-octave bandwidth (Conyers and Goodman 1997). The band-pass filter is usually applied during the data processing stage. This type of filter emphasizes the center of the filter more heavily than the ends of the filter. The high-cut and low-cut of corner frequency in the band-pass filter must be set within a range narrower than a two-octave bandwidth. The underground strata generally act like a low-pass filter, so the central frequency of returned GPR signals will be shifted to lower values (Jol 1995). Therefore, the amount of down-shifted frequency responses of received signals had to be identified for analyzing EM standing waves.

\subsection{Part I: Small-Scale Experiments}

\subsubsection{Indoor Small Scale Experiment}

Transmitted incident EM waves move toward the wall (Fig. 2a) to ensure that the superposition of incident and reflective waves generates the standing waves using a $1.5-\mathrm{GHz}$ antenna.

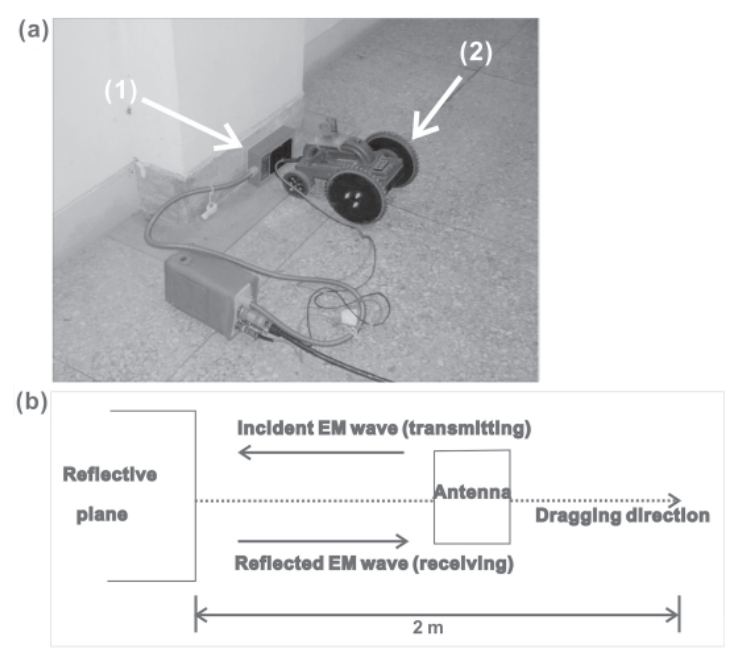

Fig. 2. (a) Demonstration of generating standing waves between a wall and a 1.5-GHz antenna (1), and survey wheel (2); (b) Schematic description of Fig. 2a. The total survey length was $2 \mathrm{~m}$. 
Consequently, the antenna (Fig. 2b) is moved away from the wall to give total survey length of 2 meters. The EM standing-wave nodes, where amplitudes are relatively minimal, were expected to appear at several points. In order to ensure accurate measurement of positions of nodes, the number of scans was set at 5 scans per centimeter. To reduce random and variable portions of reflected waves, three traces were stacked to one composite trace (Fisher et al. 1992; Grasmueck 1994). The instrument gain was employed to magnify the amplitude.

Identifying a central frequency is crucial in setting up a GPR standing-wave profile. With band pass narrower than a two-octave bandwidth, more accurate positions of nodes can be achieved (Cheng 1989). Spectral analysis of the indoor small-scale experiment showed that central frequency of the $1.5-\mathrm{GHz}$ antenna was around $1.6 \mathrm{GHz}$ (Figs. 3a, b). Band pass filter

(a)

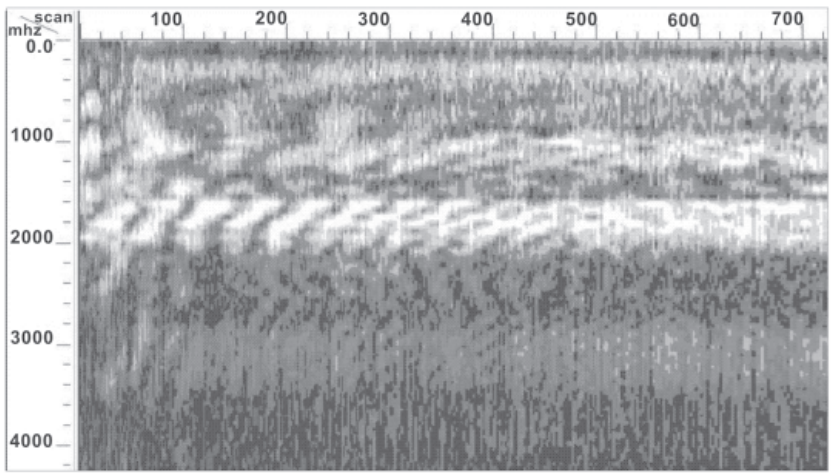

(c)

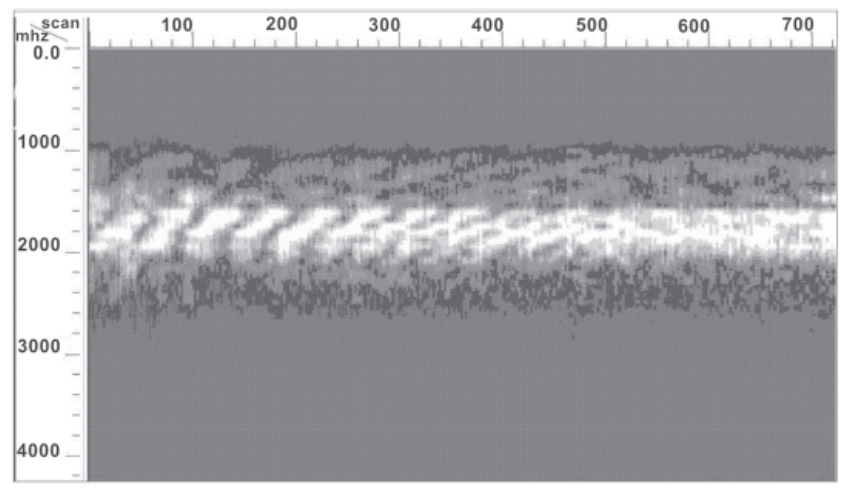

(b)

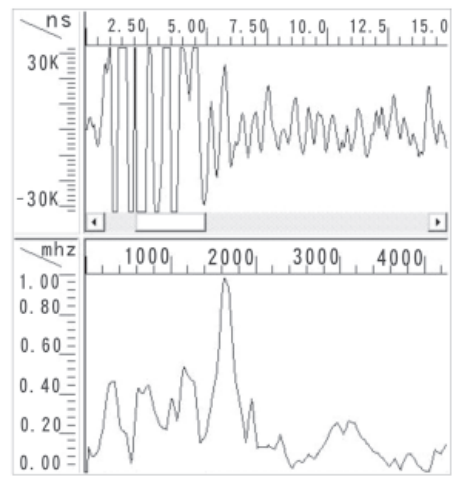

(d)

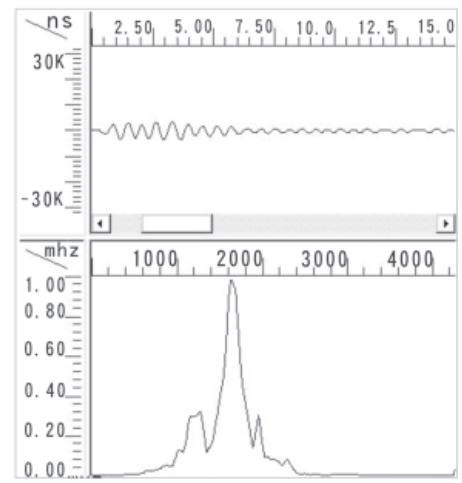

Fig. 3. Spectral analysis of recorded data: (a) raw data of frequency spectrum; (b) average responses of waveform (up) and amplitude (down) spectra obtained from whole section; (c) frequency spectrum through band pass filtering of original data within the range of 1.59 to $1.61 \mathrm{GHz}$ and (d) the corresponding waveform (up) and amplitude (down) spectra after filtering. The dominant frequency is $1.6 \mathrm{GHz}$. 
within 1.59 to $1.61 \mathrm{GHz}$ was tested (Figs. 3c, d). Notice that the waveform amplitude decreases as band-pass filter is applied (Fig. 3d, upper spectrum). Figure 4 is an enlarged section for the comparison of the original and processed GPR sections. Figure 5a shows processed sections with arrows indicating oscillating nodal points generated by EM standing waves. The positions indicated by arrows are the relative minimum of amplitude (nodes). The wide-bandwidth communicating radio noise, frequency ranging from $\mathrm{MHz}$ to $\mathrm{GHz}$ (Serway 1986), might not be thoroughly filtered out during post-acquisition data processing, and there could be some interference with recorded signals (Conyers and Goodman 1997). This might cause the nodes to be unequally spaced. In order to compare the experimental value of half an EM wavelength with the theoretical value, the positions of nodes in Fig. 5a are schematically determined in Fig. $5 b$.

\subsubsection{Outdoor Small-Scale Experiment}

To verify more evidence of EM standing waves, a 1.5-GHz antenna was employed over a 17 - and a $5.5-\mathrm{cm}$ diameter polyvinyl chloride (PVC) pipes. The pipes were buried inside a sandy box $(1.1 \times 1.0 \times 0.6 \mathrm{~m})$ at the same depth of $20 \mathrm{~cm}$. One pipe was tested in each survey. The two-way travel time was set at $10 \mathrm{~ns}$ for an $80-\mathrm{cm}$ recording depth. Automatic gain control (AGC) was used to enhance radar signals at depth. At $17 \mathrm{~cm}$ the diameter of the pipe is larger than half a dominant EM wavelength $(10.5 \mathrm{~cm})$ emitted by $1.5-\mathrm{GHz}$ antenna, but at $5.5 \mathrm{~cm}$ the diameter is smaller than half an EM wavelength. This design helps further understand the spacial restriction of generating the EM standing waves via EM waves bouncing back and forth inside the pipes. The two-way travel time vertical scale was shown as an equivalent depth by setting the relative dielectric permittivity (RDP) of dry sand at 4 .
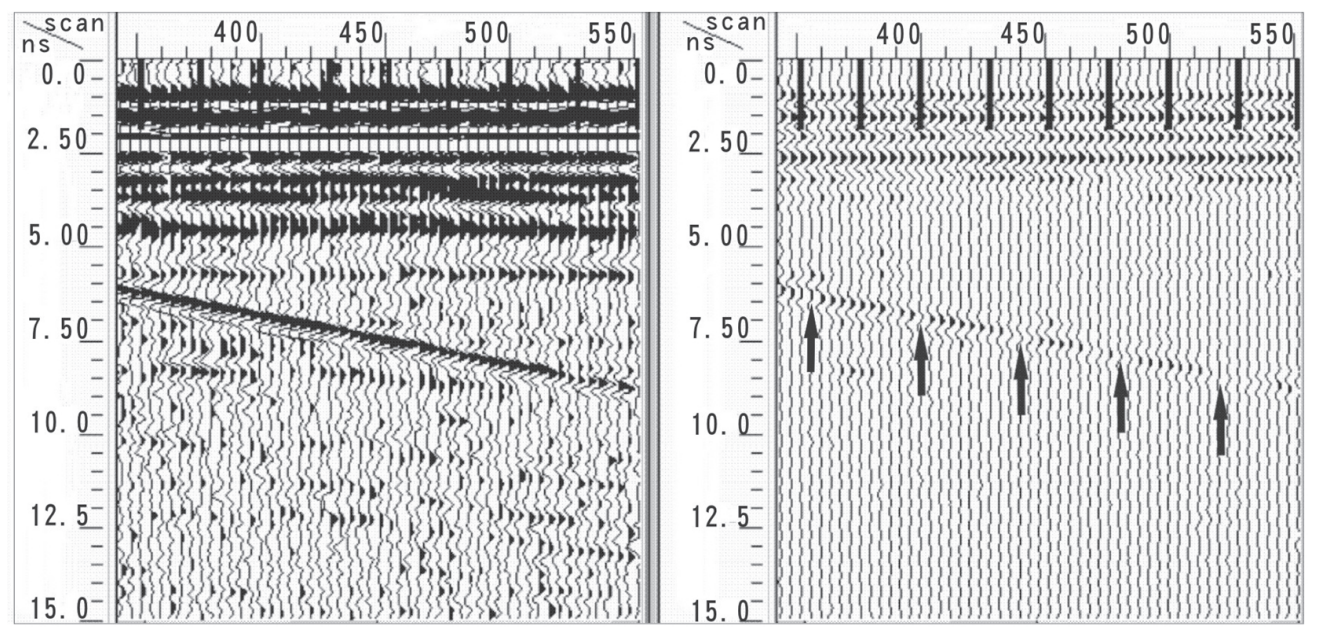

Fig. 4. Unfiltered (left) and filtered (right) GPR profiles within 1.59 to $1.61 \mathrm{GHz}$. 


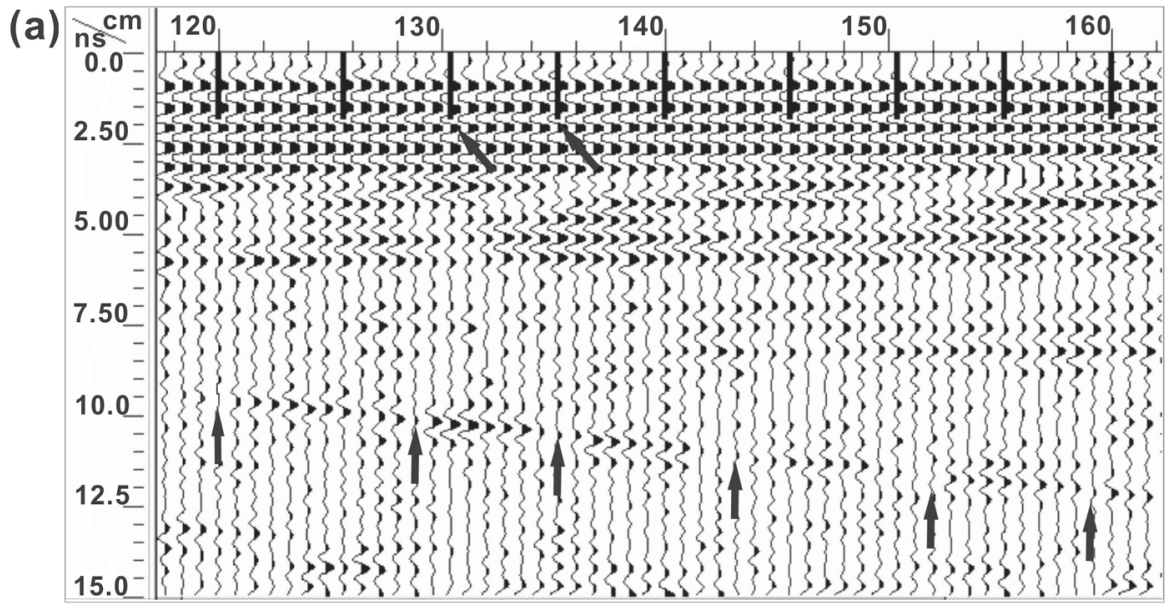

(b)

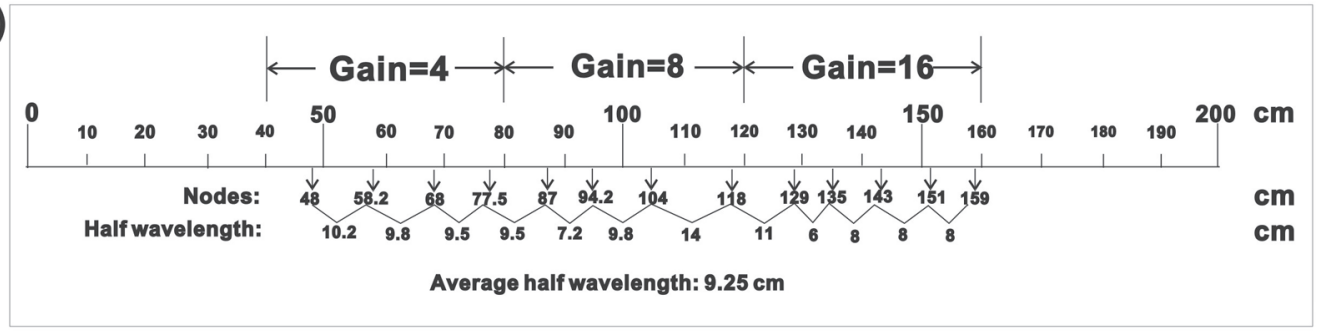

Fig. 5. GPR profile dominant by standing waves recorded from a $1.5-\mathrm{GHz}$ antenna (a) and determined nodal positions from filtered GPR section (b). The distance between 2 markers (slant arrows) is $5 \mathrm{~cm}$ and the nodal points are indicated by upward arrows.

After towing the $1.5-\mathrm{GHz}$ antenna over the $17-\mathrm{cm}$ diameter PVC pipe, the dominant frequency of reflected signals was down-shifted to around $1.4 \mathrm{GHz}$ (Fig. 6a). The band pass was set within the range of 1.39 to $1.41 \mathrm{GHz}$ and then the processed radargram presented in Fig. $6 \mathrm{~b}$. The standing-wave nodes (upward arrows in Fig. 6b) occurred by passing the receiving signals through the $0.02-\mathrm{GHz}$ bandwidth. Additional gain was also required to enhance whole reflected signals after previous data processing. However, nodal points were not generated in the HTT curve when moving the same antenna over the $5.5-\mathrm{cm}$ diameter PVC pipe (Fig. $6 \mathrm{c}$ ). The scattering cross-section of the $5.5-\mathrm{cm}$ diameter PVC pipe was smaller than that of the $17-\mathrm{cm}$ diameter pipe, so the hyperbolic signals generated from EM waves scattered by the $5.5-\mathrm{cm}$ diameter PVC pipe were "weaker" than those created from the waves emitting on the $17-\mathrm{cm}$ diameter PVC pipe. Thus, instrument gain was employed for data collected from the $5.5-\mathrm{cm}$ diameter PVC pipe. 
(a)

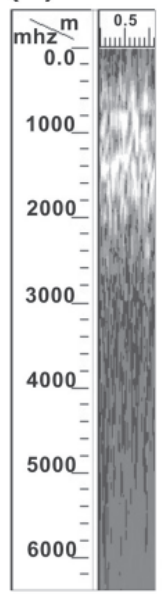

(b)

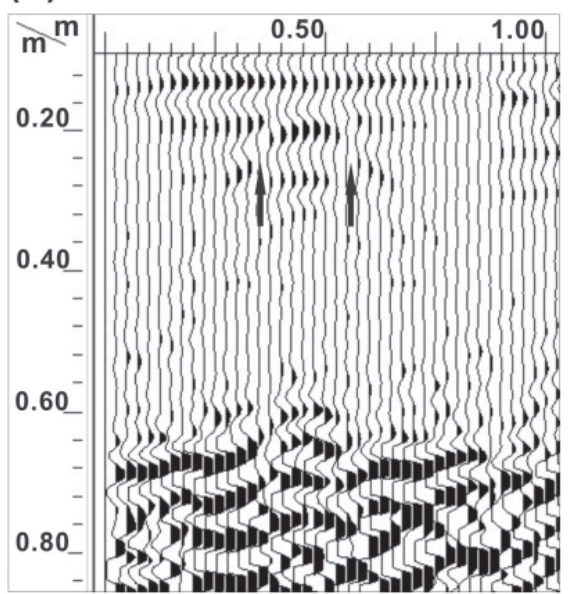

(c)

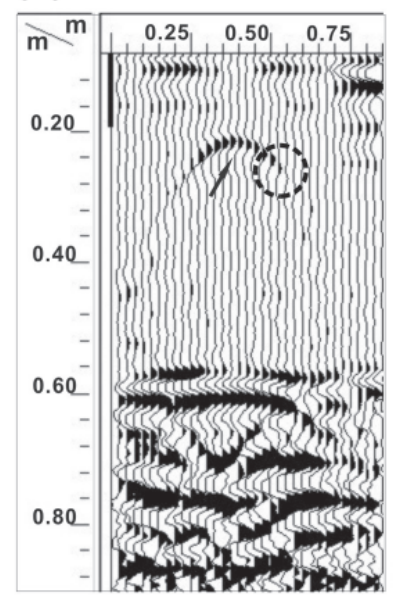

Fig. 6. Receiving frequency spectrum collected with a $1.5-\mathrm{GHz}$ antenna on a $\mathrm{PVC}$ pipe buried in sand (a), band-pass-filtered radar data with a $1.5-\mathrm{GHz}$ antenna towed cross a $17-\mathrm{cm}$ diameter PVC pipe buried $20 \mathrm{~cm}$ deep (b), and a 5.5-cm diameter PVC pipe buried $20 \mathrm{~cm}$ deep (c). Upward arrows indicate the symmetric nodal points and the slant arrow indicates the HTT curve generated from radar waves scattered by the $5.5-\mathrm{cm}$ diameter PVC pipe. Dash-circled area will be mentioned in discussion.

\subsection{Part II: Application in a Size-Measured Arched-Top Cave and Generation of HTT Curve by a Solid Diffractor}

\subsubsection{Experiment}

Another field study was carried out in Gongzihliao ancient ammunition depot (a cave with an arched top), located in Keelung, Taiwan. Since EM standing waves can be generated between two reflecting boundaries of proper lengths (i.e., integral condition of half an EM wavelength), an arched-top cave with a flat bottom was determined ideal for the requirements of these lengths. Amplitude decay rate was more significant than in part I due to the propagation of EM waves through the near-surface strata (Davis and Annan 1989). A 500-MHz antenna was employed. The survey lines for the surface antenna are indicated in Fig. 7. The survey length (x-axis) was 5 meters. The line spacing was 0.5 meter (y-axis) apart. Eighty scans were conducted per meter along each survey line. Because the penetration depth of a low frequency antenna is deeper than that of a high frequency one, total recording of the $500-\mathrm{MHz}$ antenna was set at $50 \mathrm{~ns}$ for proper penetration depth.

For identifying variation in diffraction patterns created by a solid diffractor, a bundle of five stainless steel rods was buried at $37 \mathrm{~cm}$ deep underground. Each rod was $90 \mathrm{~cm}$ long and $2 \mathrm{~cm}$ in diameter. A $500-\mathrm{MHz}$ antenna was employed to conduct the test. 


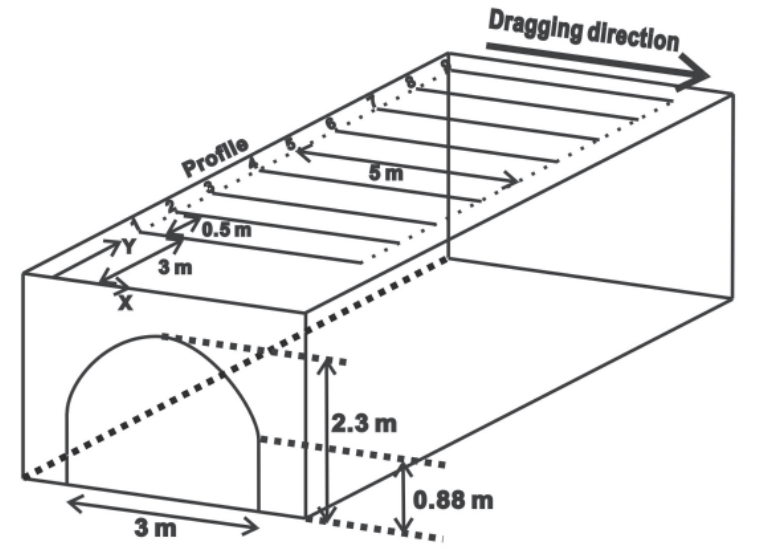

Fig. 7. Survey lines with 500-MHz antenna on the surface of the arched-top depot.

\subsubsection{Generation of an Arc-Like Curve with Standing-Wave Nodes and a HTT Curve}

Since the vertical lengths inside the arched-top cave extend continuously from 0.88 to $2.3 \mathrm{~m}$ (Fig. 7), some specific lengths meet the integral condition of half a receiving EM wavelength $(0.6 \mathrm{~m})$ of the $500-\mathrm{MHz}$ antenna. Thus, the arched-top cave with a flat bottom provides proper vertical lengths for standing-wave analysis. The down-shifted frequency range from 500 to $250 \mathrm{MHz}$ indicates that the near-surface backfilled layer is a highly attenuated media (Fig. 8a). The band pass was set within 240 to $260 \mathrm{MHz}$ (Fig. 8b). Figures 9a and b show the

(a)

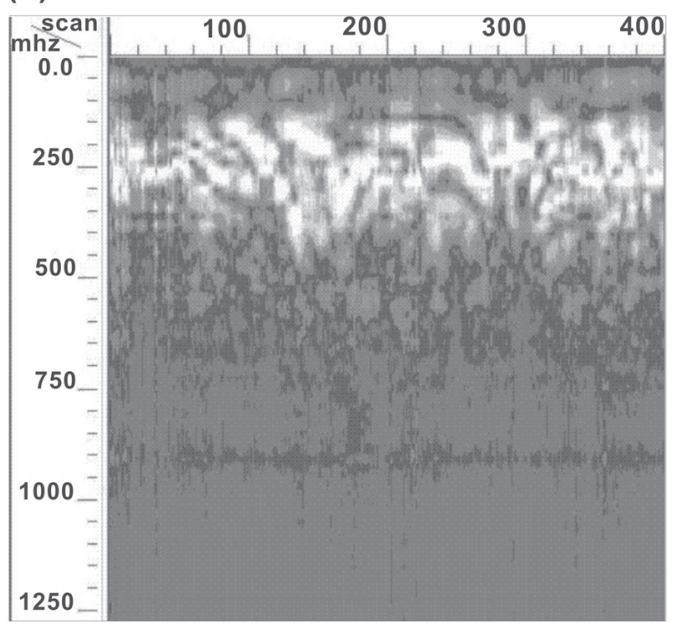

(b)

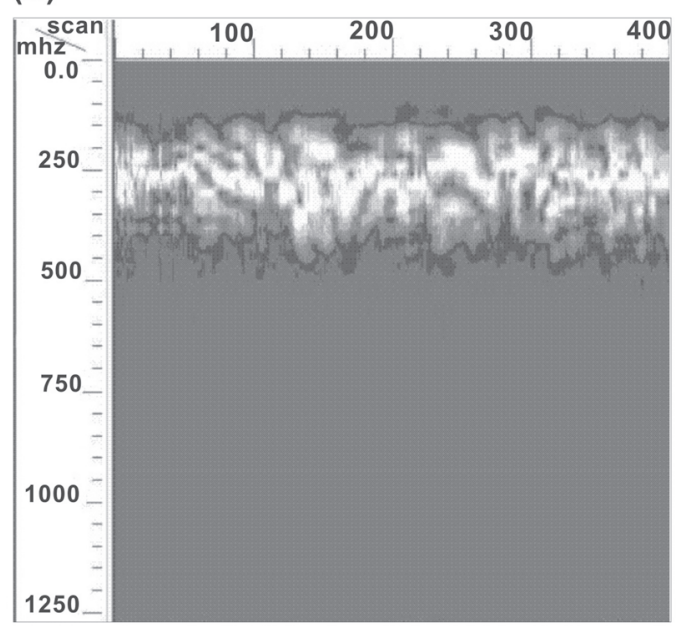

Fig. 8. Spectral process of GPR data collected at the Gongzihliao site. For a $500-\mathrm{MHz}$ antenna before (a) and after (b) applying the band pass filter within the range of 240 to $260 \mathrm{MHz}$. 

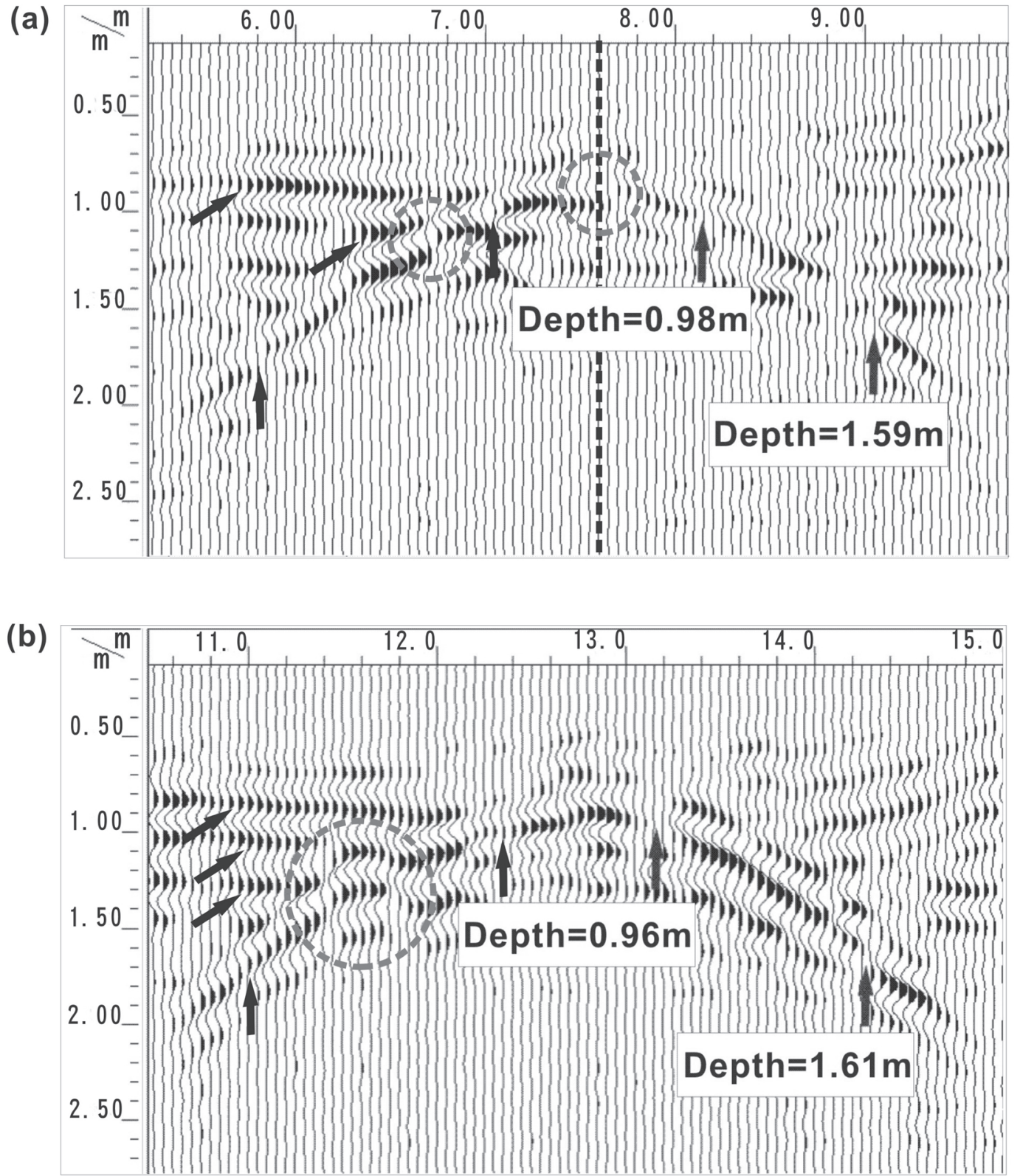

Fig. 9. GPR radar sections acquired at profiles 2 (a) and 3 (b) with a $500-\mathrm{MHz}$ antenna. The location of each survey line is shown in Fig. 7. The standingwave nodes (upward arrows) are symmetric to the center axis (Fig. 9a, dash line). Slant arrows indicate high EM energy reflection in the backfill. 
profiles along lines 2 and 3 (Fig. 7). The reflected signals from backfill (Fig 9, slant arrows) might interfere with EM standing-wave signals on the arc-like boundary so the phases of standing-wave signals were shifted (three circled area in Fig. 9). Since the downward incident EM waves were perpendicular to the flat bottom, the analysis of EM standing waves in 1D is feasible. Thus, the depth interval between two successive nodes (arrows) on each profile corresponds to a half EM wavelength. The experimental values of half EM wavelengths were 0.61 and $0.65 \mathrm{~m}$, or $0.63 \mathrm{~m}$ in average.

Figure 10a is the depth-converted GPR section. With a 500-MHz antenna towed over the arched-top cave, the rods-scattered HTT curve (indicated by downward arrow) and the archedroof-generated arc-like curve (solid curve) are identified. The slanted arrows (Fig. 10a) are the multiple reflections of signals multi-generated by the arched top (solid curve). The positions indicated by upward arrows on the solid curve (Fig. 10a) are standing-wave nodes. Figure 10b shows a migrated profile of Fig. 10a. Note that the rods-scattered HTT curve has been collapsed and moved to a depth of $37 \mathrm{~cm}$ (circled area); the two sides of the arc-like curve have also been destroyed except for the strong signals at the apex (arrow in Fig. 10b). The estimated relative dielectric permittivity is 8 based on the well-constrained depth of steel rods and two-way travel time calculation.

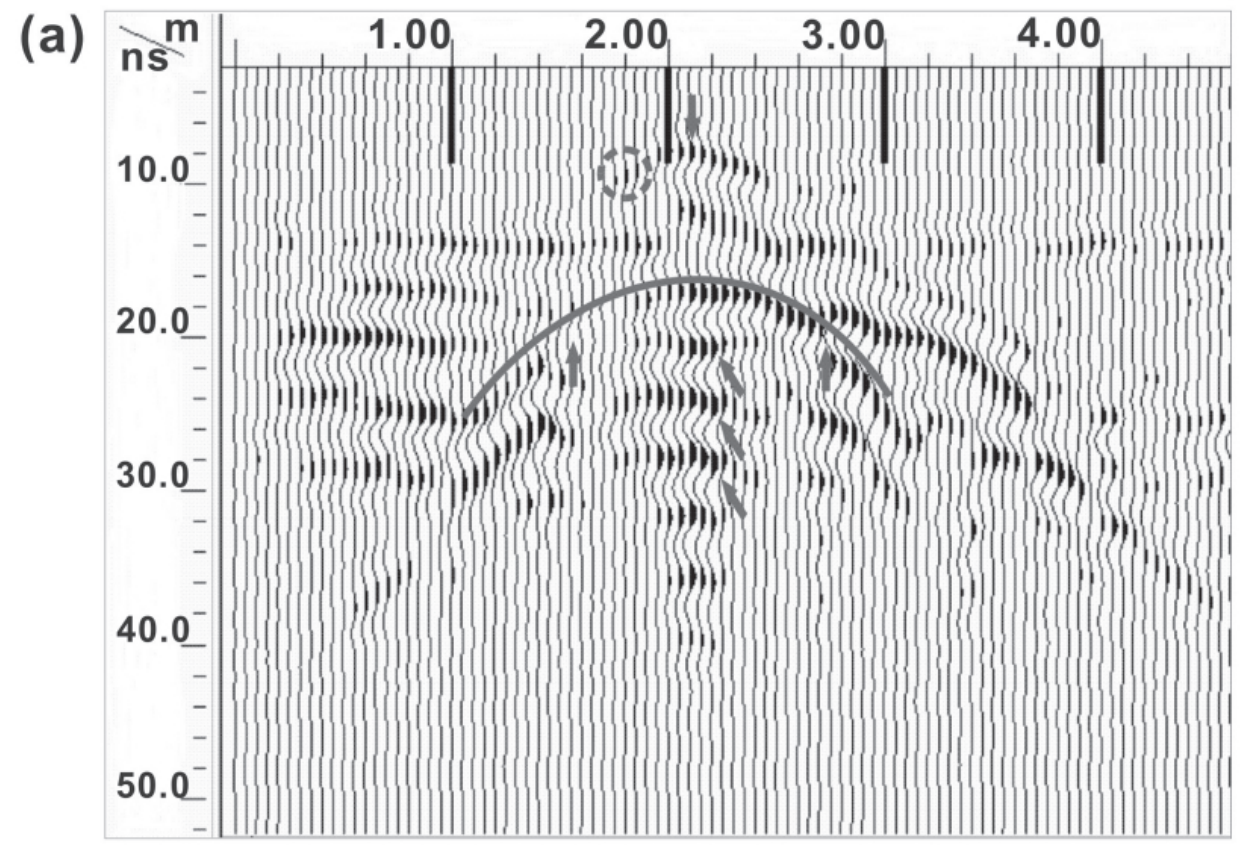

Fig. 10. GPR data collected over an arched-top cave: (a) EM wave traveling time, $7 \mathrm{~ns}$ from the surface to the apex of the HTT curve (indicated by a downward arrow) where the bundle was buried, and (b) migration on (a). 


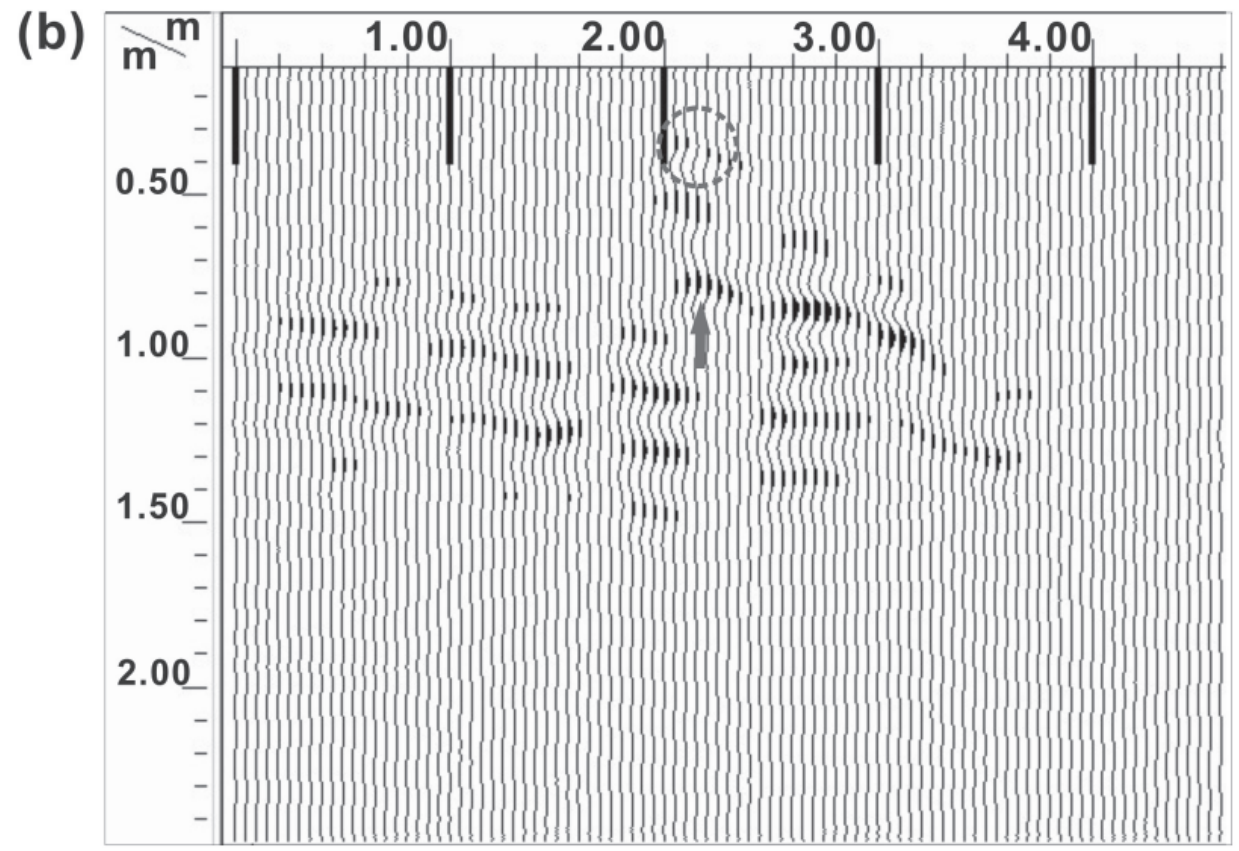

Fig. 10. (Continued)

\subsection{Part III: Applying in the Field Study - a Fractured Granitic Rock and a Deteriorat- ing Coastal Structure}

\subsubsection{Experiment}

The first experimental site in this part was located at Maoshan, southwest Kinmen. This area is characterized mainly by uplifted granitic rocks formed by mountain building process during early Cretaceous (Chen et al. 2002). Fractures inside the rocks were created after the relaxation of stress and unloading (Marre 1986; Engelder 1985). The purpose of this experiment was to detect EM standing waves inside an unreachable cave. An open fracture inside a large granitic rock without regolith on the surface (Fig. 11a), a 2D survey line with 7 meters long (Fig. 11b) on the flat surface was conducted. A 500-MHz GSSI antenna with a recording window of 60 ns was utilized in conjunction with an AGC.

The other experiment was carried out on the surface of a fractured wharf (Fig. 12). At this location sea water has seeped into the backfill behind the retaining wall reducing the effective stress of the backfill soil, and thus voids have been created by soil liquefaction. A 2D-GPR (500-MHz antenna) 2-m survey line was conducted over the open void (Fig. 12, white arrow). Since the rate of amplitude decay is significant in highly conductive seawater-soaked soil, this 
(a)

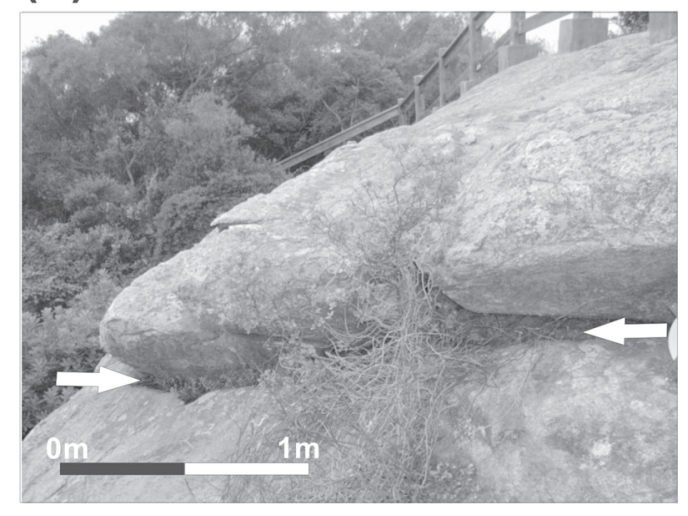

(b)

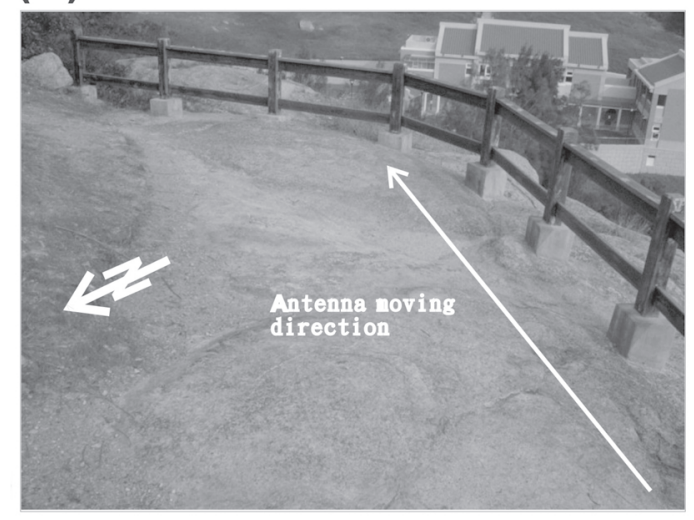

Fig. 11. A flat fracture, $1 \mathrm{~m}$ below the surface and indicated by arrows, is located in a big granitic rock (a) and the 2D GPR survey carried out on the surface of a massive granitic rock in Maoshan, Kinmen (b).

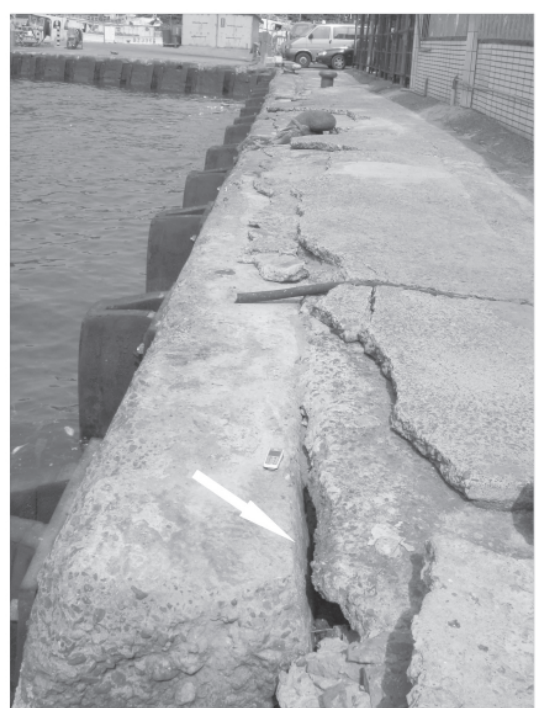

Fig. 12. A void, indicated by arrow, formed inside the deteriorating wharf at Nanfangao site, Taiwan.

might induce a radar reflection-free area under the sea water table (Chen and Chow 2007). Consequently, the recording depth was set within 3 meters and an AGC system utilized. Thirty three scans were conducted for background removal to reduce antenna ringing and horizontal banding across the image. 


\subsubsection{Standing Waves in Fracture and Void Detection}

For data collected from the Maoshan site in the Kinmen area, the predominant frequency of returned radar signals is around $250 \mathrm{MHz}$ (Fig. 13a). The band pass was set within 240 to $260 \mathrm{MHz}$. Figure 13b shows the GPR profile collected over a mass of fractured granitic rock. The location of the fracture is indicated by the right dashed circle (Fig. 13b). The downward arrows show the positions of the standing-wave nodes, indicating that EM standing waves were created inside the underground cave, while the apex of the HTT curve is indicated by an upward arrow.

Figure 14a is the original frequency spectrum acquired from the fractured wharf in Nanfangao fishing port, Taiwan. A band pass within the range 280 to $300 \mathrm{MHz}$ was employed to process the raw data. Figure $14 \mathrm{~b}$ is the processed wiggle-trace representation employing the instrument gain in whole profile. The width of the open void was $0.63 \mathrm{~m}$ (Fig. 12) which corresponds to its location in the radargram (Fig. 14b) with coordinates from 0.30 to $0.95 \mathrm{~m}$. Top of the void is associated with high EM energy reflections (slant arrow in Fig. 14b). The occurrence of a nodal point (upward arrow) reveals that the EM standing waves were generated in this resonance cavity (Fig. 14b).

\section{DISCUSSION}

\subsection{Identification of Nodal Points and Spacial Restriction in Small-Scale Experiment}

To verify how EM standing waves could be created in a cave and fracture site, we designed a series of experiments in this study. Our experience from indoor testing indicates that passing raw data through a band pass narrower than a two-octave bandwidth is critical for our analysis. Applying the band pass filter within 1.59 to $1.61 \mathrm{GHz}$ makes nodal points more recognizable. Thus the phenomenon of standing waves exists when an empty space was detected by using GPR. This procedure for obtaining the experimental value of half an EM wavelength could then be used for comparison with the theoretical value of half an EM wavelength of the antenna. From Fig. 5b, the experimental value of half an EM wavelength is 9.25 $\mathrm{cm}$ on average. Since the central frequency of receiving signals of the $1.5-\mathrm{GHz}$ antenna is 1.6 $\mathrm{GHz}$, the theoretical value of half an EM wavelength is $9.37 \mathrm{~cm}$, as calculated by the following equation: $\lambda=\frac{c}{f}$, where $\lambda$ is the wavelength, $c$ is the speed of EM waves traveling in air or vacuum and $f$ is the frequency of the EM waves. The experimental value is $1.2 \%$ less than the theoretical one. Since the amplitude variation is not clear outside the range 40 to $160 \mathrm{~cm}$ for marking the accurate positions of nodes, the values beyond these two ends were neglected.

There is a spacial restriction in generating the EM standing waves. Hence an outdoor small-scale experiment was designed (part I) whereby a 1.5-GHz antenna was passed over two sand-buried hollow PVC pipes, one of 17-cm diameter and the other of $5.5 \mathrm{~cm}$. At $17-\mathrm{cm}$ the diameter is larger than half an EM wavelength $(10.5 \mathrm{~cm})$ but at $5.5-\mathrm{cm}$ the diameter is smaller than half an EM wavelength. The occurrence of symmetric standing-wave nodes shown in the radargram collected from a 17-cm diameter PVC pipe (Fig. 6b, upward arrows) reveals the 

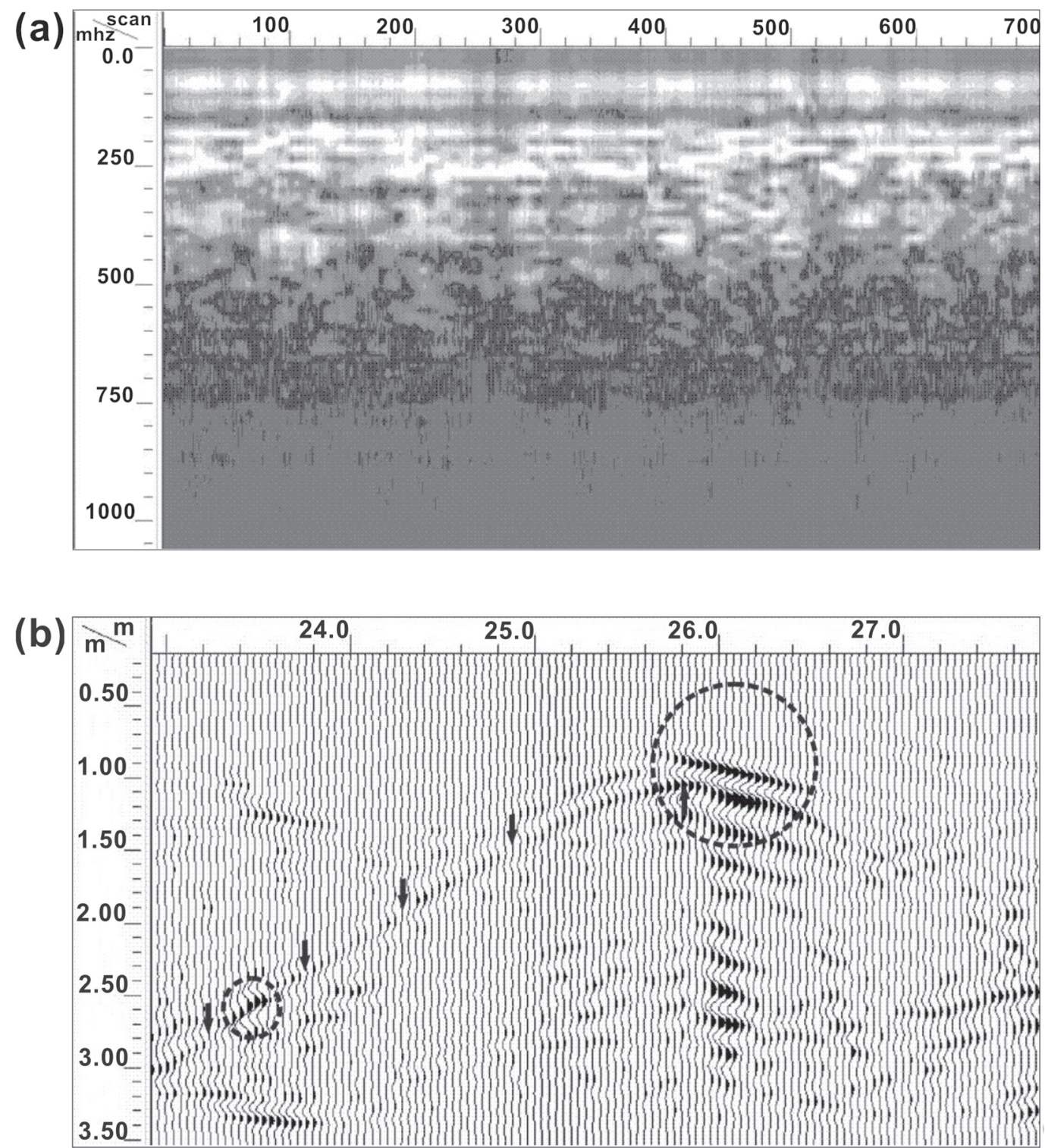

Fig. 13. Receiving frequency spectrum (around $250 \mathrm{MHz}$ ) of the $500-\mathrm{MHz}$ antenna scanning on the fractured granitic rock (a) and the GPR profile collected over the open fracture (b). The HTT curve with standing-wave nodes (downward arrows) was generated. Top of the HTT curve is indicated by the upward arrow and dash-circled areas were mentioned in the text. 

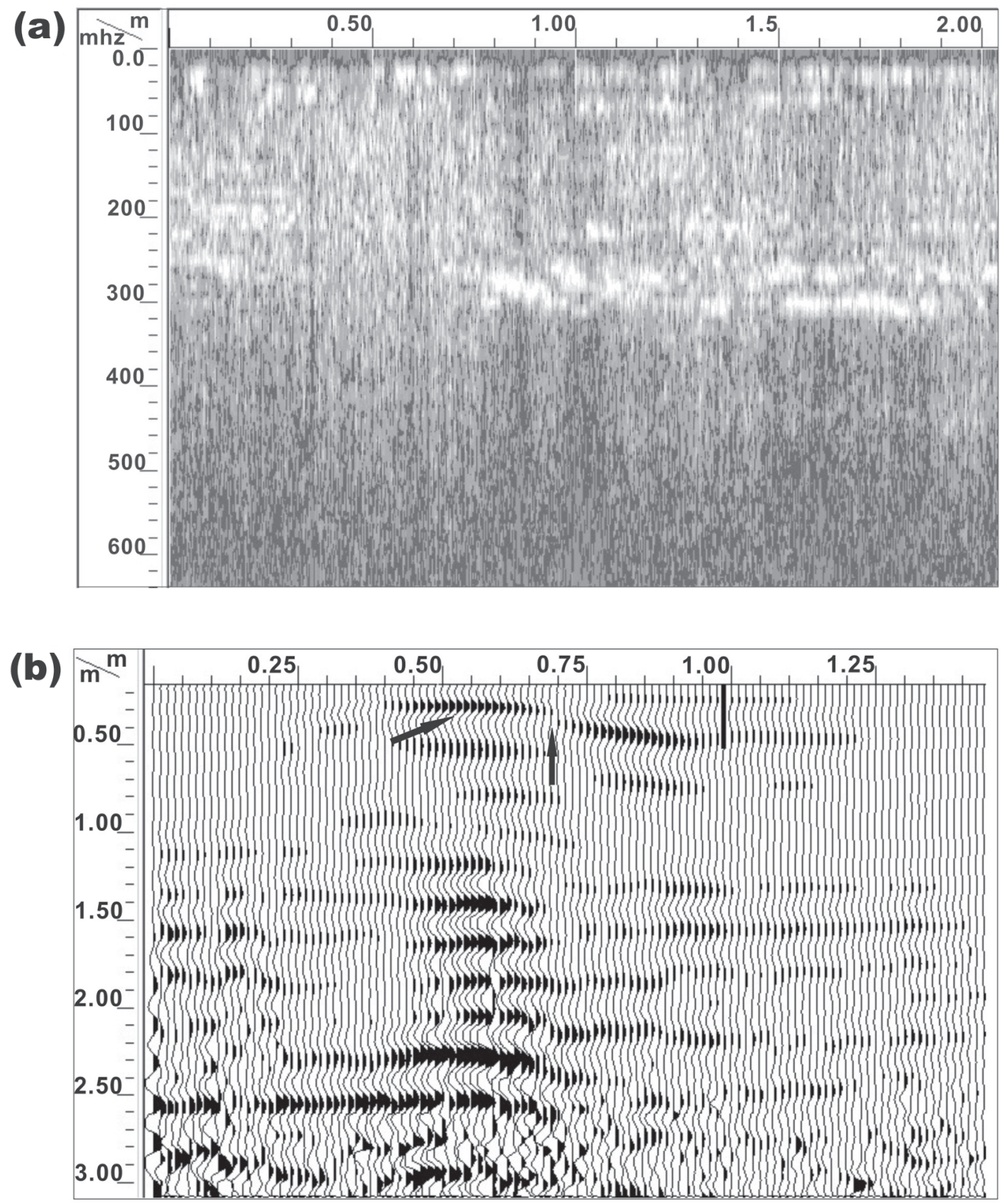

Fig. 14. Receiving frequency spectrum (around $300 \mathrm{MHz}$ ) of the $500-\mathrm{MHz}$ antenna collected at the deteriorating wharf, Nanfangao (a) and the radargram acquired at the same site (b). The upward arrow indicates the generated nodal point and top of the void is indicated by the slant arrow. 
generation of EM standing waves inside this vacant space. However, GPR data acquired from the 5.5-cm diameter PVC pipe does not show any nodal points (Fig. 6c). This phenomenon indicates that the EM standing waves can only be generated inside a vacant space where the widest inner length is larger than half an EM wavelength. When moving the 1.5-GHz antenna over the $5.5-\mathrm{cm}$ diameter PVC pipe, the distances varying between the antenna and the in-sand pipe were from 54 to $20 \mathrm{~cm}$. Some of the distances satisfied the integral condition of half an EM wavelength $(10.7 \mathrm{~cm})$ but the nodal points were not created. This could be the result of EM-wave attenuation in air being less than that in sand whereby the air-filled space provides stronger EM-wave resonant signals than the space filled with sand does.

\subsection{Data Interpretation for the Wavelength of Receiving Signals in Gongzihliao}

At the Gongzihliao site, a 500-MHz antenna was used and the corresponding receiving dominant frequency was $250 \mathrm{MHz}$. The flat bottom of the arched-top cave at this site is perpendicular to the central axis of the cone-like EM-wave radiations. Considering the superposition of EM incident and reflected waves in 1D, the downward-propagating EM waves would be reflected from the bottom and then interfere with the incoming EM waves (downward and upward arrows under the GPR in Fig. 15). The flat bottom is to make similar 1D EM-wave reflections as those of the indoor small-scale experiment. Consequently, EM-standing waves were generated in one dimension when vertical lengths inside the cave satisfied the integral condition of half an EM wavelength (Fig. 15). On average, the experimental value of half an EM wavelength propagating in the arched-top cave for the 500-MHz antenna was $63 \mathrm{~cm}$ (Fig. 15). Although radar waves passed through the attenuated stratum $(\mathrm{RDP}=8)$, the generation of standing waves inside the arched-top cave were still visible. The theoretical value of half an EM wavelength filtered by a single stratum (a layer of backfill) with the $500-\mathrm{MHz}$ antenna was $60 \mathrm{~cm}(250 \mathrm{MHz}$ of central frequency).

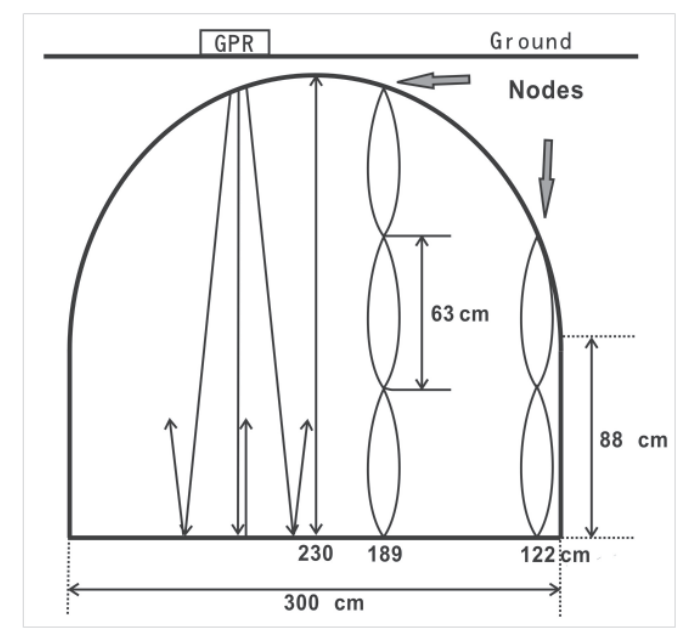

Fig. 15. Diagrams of standing waves generated inside the depot with an arched roof and a flat bottom for a receiving frequency of $250 \mathrm{MHz}$ with a $500-\mathrm{MHz}$ antenna. 


\subsubsection{Interpretation of the HTT and Arc-Like Image by Nodal Points}

Migration is often used to collapse diffraction signals; however, important but weak events may vanish in the process (Fig. 10b). Thus, a HTT curve generated by emitting radar waves on an underground solid diffractor and arc-like curves generated by emitting waves on a symmetrical arched-top pipe or cave need to be interpreted before processing the migration.

When HTT curves were generated from the radar waves scattered by the bundle of steel rods (Fig. 10a, downward arrow), standing-wave nodes were not seen. However, symmetric nodal points were generated by a 500-MHz antenna surveying the arched-top cave. This again verifies that symmetric nodal points could occur as an antenna surveys a symmetrical archedtop vacant space with the widest inner length being larger than half an EM wavelength. Therefore, in accordance with the generation of symmetric nodes in arc-like curves (Fig. 9), the space under the curves should be empty to allow the generation of standing waves. This explanation indicates that arc-like curves represent the arched top of a cavity but not a boundary between strata. Arc-like curves vanish after migration. This process might induce misinterpretation of radargrams.

Passing the reflected signals through the band-pass filter with bandwidth narrower than two octaves obtains nodes for easier identification. The symmetric nodal points in the HTT curve collected from surveying an in-sand PVC pipe with 17-cm diameter (Fig. 6b) are more recognizable than those in arc-like curve acquired from surveying on the arched-top cave covered by a layer of backfill (Fig. 9). This is likely due to the dry sand being more homogeneous than the backfill, thus those regions in the sandy box from a depth of 10 to $60 \mathrm{~cm}$ (bottom of the sandy box) are almost without reflections (Figs. 6b, c). The high energy reflections of EM signals in backfill (indicated by slant arrows in Fig. 9) may disturb the locating of nodal points. In the test of the arched-top cave at Gongzihliao, because the antenna was towed directly above the cave (Fig. 7), the arc-like curve (labeled by solid curve in Fig. 10a) with standingwave nodes was of similar shape to the cavity top, not a HTT curve from EM waves scattered by a point source.

\subsection{Standing Waves in a Fractured Granitic Rock and a Deteriorating Wharf}

When HTT curves generate from radar waves scattered by a hollow object with the widest inner length smaller than half an EM wavelength (Fig. 6c, slant arrow) or by a solid diffractor (Fig. 10a, downward arrow), the radar signals on the curve tails gradually diminish (Figs. 6c, 10a, dashed circles) due to a long EM-wave propagating distance causing more attenuation of signals (Stevens et al. 1995). However, the signals on the tail of the HTT curve in Fig. 13b (left dashed circle) are still visible. This reveals EM-wave resonance occurring inside the fracture of the granitic rock which enhanced the reflected signals. The phenomenon also infers the widest inner length in the fracture is larger than half an EM wavelength.

Figure 16 illustrates the geometrical relationships between radar energy paths along with the shape of the fracture in the granitic rock, Kinmen. The observable diffraction tail shown in Fig. 13b (left circled area) was mainly caused by the interference of EM standing waves and scattered radar waves. Standing waves were generated by the outward and backward EM waves inside the fracture. The resonant length $(\mathrm{L})$ between two fixed ends inside the cave decreased 


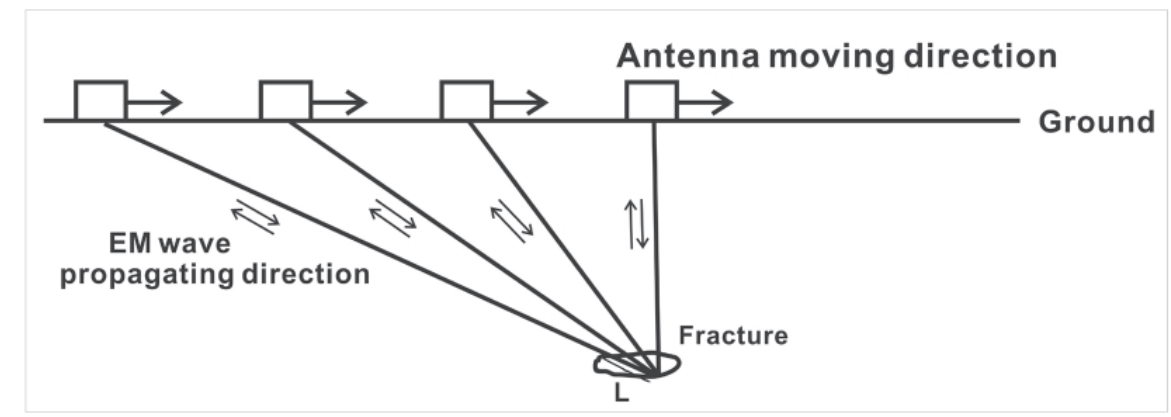

Fig. 16. Diagram of certain EM-wave propagating directions of a 500-MHz antenna detecting at a granite surface over a fractured underground.

as the antenna moved toward the right. If the length (L) just fits the integral condition of half an EM wavelength emitted from the 500-MHz antenna, the nodes will appear. It should be noted that the downward spreading angle of the cone-like radiation from the 500-MHz antenna was $120^{\circ}$ (Engheta et al. 1982; Goodman 1994). The scale of the 1m-depth fracture from the radargram in Fig. 13b (about $0.8 \mathrm{~m}$ in length) is estimated to be one tenth of the survey distance $(8 \mathrm{~m})$. Thus, the approaching of the antenna toward the location atop the fracture is similar to surveying an underground diffractor (Fig. 16). The part of the cone-like radiation passing through the cave was as narrow as a beam. The 1D EM-wave beams chosen here (Fig. 16) were for generating standing waves due to other directions of the beams being outside the fracture and consequently not able to create such a phenomenon. This situation was similar to surveying a hollow diffractor with the widest inner length being larger than half an EM wavelength $(60 \mathrm{~cm})$; therefore, the HTT curve with standing-wave nodes was generated (Fig. 13b).

Similar GPR responses were acquired from towing the $500-\mathrm{MHz}$ antenna over a void inside a deteriorating wharf at Nanfangao. Measuring by ruler, the field-observed void length and void-bottom depth were 0.63 and $0.92 \mathrm{~m}$ (Fig. 12). Since half a dominant receiving EM wavelength is $0.5 \mathrm{~m}$ and the widest inner length inside the void is larger than that, the occurrence of EM standing waves inside the void was expected. This generation of the nodal point in the radargram (upward arrow in Fig. 14b) verified this.

\section{CONCLUSIONS}

By passing the GPR receiving signals through a band-pass filter of bandwidth narrower than two octaves, required standing-wave nodes could be recognized, thus a more precise central frequency could also be obtained. The interval of the nodal points acquired from tests of towing a $1.5-\mathrm{GHz}$ antenna away from a wall and dragging a $500-\mathrm{MHz}$ antenna over the surface of an arched-top cave with a flat bottom was used to estimate the EM wavelength. 
Comparing experimental conditions with actual field conditions, the dry sand of our experimental sandbox environment was more homogeneous than backfill under field conditions; consequently, the radargram collected from the sand was almost without reflections unlike the backfill. Therefore, standing-wave nodes observed in the less-signal-disturbed radargram collected from our in-sand PVC pipe experiment are more apparent than those acquired from an arched-top cave covered by a layer of backfill. With standing-wave nodes, the HTT curve indicates an underground hollow diffractor where the widest inner length in the vacant space is larger than half a dominant EM wavelength, while the one without the nodal points signifies a hollow object with the widest inner length smaller than half an EM wavelength or a solid diffractor. These responses could be used to verify the estimation of void volume in GPR mapping of the fracture, voids or cavities. The vacant space under the symmetrical arched-top cave could be illustrated by the symmetric nodal points on the arc-like curves in GPR wiggle representation. This phenomenon could be used to interpret the radargram before employing the migration. Thus, the important but weak events could be kept. Identifying the nodal points in HTT or HTT-like curves in radargram may assist the GPR interpreting work for underground tunnels, drainages, cavities, fractures or solid objects.

Acknowledgements The authors are indebted to the National Science Council for its support of this research (project number: NSC 93-2119-M-019-001). Thanks are also due to Mr. J. G. Sie and Mr. C. J. Yao for the assistance during site data collection and Mr. S. K. Chang for the software instruction.

\section{REFERENCES}

Beres, M., M. Luetscher, and R. Olivier, 2001: Integration of ground-penetrating radar and microgravimetric methods to map shallow caves. J. Appl. Geophys., 46, 249-262.

Bruschini, C., B. Gros, F. Guerne, P. Y. Piece, and O. Carmona, 1998: Ground penetrating radar and imaging metal detector for antipersonnel mine detection. J. Appl. Geophys., 40, 59-71.

Cai, J., and G. A. McMechan, 1999: 2D ray-based tomography for velocity, layer shape, and attenuation from GPR data. Geophysics, 64, 1579-1593.

Chamberlain, A. T., 2000: Cave detection in limestone using ground penetrating radar. $J$. Archaeol. Sci., 27, 957-964.

Chen, W. S., H. C. Yang, X. Wang, and H. Huang, 2002: Tectonic setting and exhumation history of the Pingtan-Dongshan Metamorphic Belt along the coastal area, Fujian Province, Southeast China. J. Asian Earth Sci., 20, 829-840.

Chen, Y. L., and J. J. Chow, 2007: Ground penetrating radar signal processing improves mapping accuracy of underground voids and seawater table - An application in deteriorating coastal structure, Nanfangao Port, Taiwan. Environ. Geol., 53, 445-455.

Cheng, D. K., 1989: Field and wave electromagnetics, Addison-Wesley, 388-399.

Conyers, L. B., and D. Goodman, 1997: Ground-penetrating radar: An introduction for archaeologists, AltaMira Press, 40 pp. 
Daniels, D. J., 2004: Ground Penetrating Radar, $2^{\text {nd }}$ Ed., The Institution of Electrical Engineers, 278-282.

Davis, J. L., and A. P. Annan, 1989: Ground-penetrating radar for high-resolution mapping of soil and rock stratigraphy. Geophys. Prosp., 37, 531-551.

Du, H. I., 2000: The application of ground-penetrating radar in a serpentine quarry. Master Thesis, National Central University, Chung-Li, Taiwan, ROC, 87 pp. (in Chinese)

Engelder, T., 1985: Loading paths to joint propagation during a tectonic cycle: An example from the Appalachian Plateau, USA. J. Struct. Geol., 7, 459-476.

Engheta, N., C. H. Papas, and C. Elachi, 1982: Radiation patterns of interfacial dipole antennas. Radio Sci., 17, 1557-1566.

Fisher, S. C., G. A. McMechan, and A. P. Annan, 1992: Acquisition and processing of wideaperture ground-penetrating radar data. Geophysics, 57, 495-504.

Goodman, D., 1994: Ground-penetrating radar simulation in engineering and archaeology. Geophysics, 59, 224-232.

Grandjean, G., and J. C. Gourry, 1996: GPR data processing for 3D fracture mapping in a marble quarry (Thassos, Greece). J. Appl. Geophys., 36, 19-30.

Grasmueck, M., 1994: Application of seismic techniques to discontinuity mapping with groundpenetrating radar in crystalline rock of the Gotthard Massif, Switzerland. Proceedings of the fifth international conference on ground penetrating radar, 1135-1139, Waterloo Centre for Groundwater Research, Waterloo, Canada.

Grasmueck, M., 1996: 3-D ground-penetrating radar applied to fracture imaging in gneiss. Geophysics, 61, 1050-1064.

GSSI (Geophysical Survey System Inc.), 2003: Radan for windows (version 5.0, user's manual), 39-57.

Inan, U. S., and A. S. Inan, 1999: Electromagnetic Waves, Prentice Hall, 123-125.

Jackson, J. D., 1998: Classical Electrodynamics ( $2^{\text {nd }}$ Ed.), John Wiley, 356 pp.

Jol, H. M., 1995: Ground penetrating radar antennae frequencies and transmitter powers compared for penetration depth, resolution and reflection continuity. Geophys. Prosp., 43, 693-709.

Lin, M. H., 2000: Application of ground penetrating radar in void analysis. Master Thesis, National Cheng Kung University, Tainan, Taiwan, ROC. (in Chinese)

Malagodi, S., L. Orlando, S. Piro, and F. Rosso, 1996: Location of archaeological structures using GPR method: Three-dimensional data acquisition and radar signal processing. Archaeol. Prosp., 3, 13-23.

Marre, J., 1986: The Structure Analysis of Granite Rocks, Elsevier, 50 pp.

Meier, E., P. Huggenberger, W. Stiefelhagen, I. Müller, and R. Christe, 1997: Geophysical methods as a tool for speleological and geotechnical investigation in Karst Maira, Plateau de Bure (JU), Switzerland. Proceedings of $12^{\text {th }}$ International Congress of Speleology, Switzerland, 2, 221-224.

Nakashima, Y., H. Zhou, and M. Sato, 2001: Estimation of groundwater level by GPR in an area with multiple ambiguous reflections. J. Appl. Geophys., 47, 241-249.

Peng, D. W., and S. F. Ling, 2005: Microphone-free measurement of acoustic absorption coefficient of materials using a standing wave tube. Meas. Sci. Technol., 16, 1069-1074. 
Porsani, J. L., W. A. Sauck, and A. O. S. Junior, 2006: GPR for mapping fractures and as a guide for the extraction of ornamental granite from a quarry: A case study from southern Brazil. J. Appl. Geophys., 58, 177-187.

Prabhakar, V., and V. Sundar, 2001: Standing wave pressures on walls. Ocean Eng., 28, 439455.

Serway, R. A., 1986: Physics for scientists and engineers, Saunders College Publishing, 786 pp.

Somer, L., N. Linford, W. Penn, A. David, L. Urry, and R. Walker, 2005: Fixed-frequency radio-wave imaging of subsurface archaeological features: A minimally invasive technique for studying archaeological sites. Archaeometry, 47, 159-173.

Stevens, K. M., A. L. Holloway, and N. M. Soonawala, 1995: The application of ground penetrating radar for mapping fractures in plutonic rocks within the Whiteshell Research Area, Pinawa, Manitoba, Canada. J. Appl. Geophys., 33, 125-141.

Chen, Y. L., J. J. Chow, and H. W. Chen, 2007: Analysis of standing waves on GPR hyperbolic travel-time responses - Case studies in a fractured granitic rock and a deteriorating coastal structure. Terr. Atmos. Ocean. Sci., 18, 879-900, doi: 10.3319/TAO.2007. 18.5.879(T). 